\title{
Editorial
}

\section{Ecology and conservation of freshwater fish: time to act for a more effective management}

\author{
Micaela Mota ${ }^{1}$, Ronaldo Sousa ${ }^{1,2}$, Jorge Araújo ${ }^{1}$, Catarina Braga ${ }^{1}$, Carlos Antunes ${ }^{1,3}$ \\ ${ }^{1}$ CIMAR-LA/CIIMAR - Interdisciplinary Centre of Marine and Environmental Research, University of Porto, Porto, Portugal \\ ${ }^{2}$ CBMA-Centre of Molecular and Environmental Biology, Department of Biology, University of Minho, Braga, Portugal \\ ${ }^{3}$ Aquamuseum of River Minho, Parque do Castelinho, Vila Nova de Cerveira, Portugal
}

Freshwater habitats may account for less than $0.01 \%$ of the Earth's total surface but they play an important role in fundamental ecosystem functions and services, besides sustaining an overwhelming diversity of species (Vörösmarty et al. 2010; Carpenter et al. 2011). Based on current assessments and projections, there may be between 25,000 and 40,000 species of fish in the world, including at least 14,000 freshwater species (Kottelat \& Freyhof 2007), and some 300 new species of fish being described every year currently. Every continent has its own distinctive fish fauna whose distribution patterns are the result from physical barriers disrupting past dispersal pathways, as well as physiological and behavioral adaptations to cope with environmental and habitat-specific characteristics (Lucas \& Baras 2001; Helfman et al. 2009). This situation imposes different evolutionary processes resulting in a high genetic differentiation responsible for a high number of local endemism.

Although freshwater fish exhibit great diversity and are responsible for several important functions, their specific roles are still poorly understood. Besides being valuable resources for food, sport and having high ornamental value, they are responsible for fundamental ecological processes and functions such as nutrient cycling, trophic dynamics, productivity, ecosystem engineering and ecosystems connection through migrations, among others. Regrettably, major threats to fish diversity are numerous and may interact with each other, thus further complicating the situation (Dudgeon et al. 2006). Examples of identified threats, to name a few, are overexploitation and flow modification, habitat loss and fragmentation, deleterious effects of agriculture, introduction of nonnative species, climate change and pollution including eutrophication (Dudgeon et al. 2006).
Overexploitation of freshwater ecosystems receives much less attention than marine ecosystems although the consequences could be similar if not worse (Allan et al. 2005). Illegal fishing using, for example, pesticides, electrofishing and dynamite are responsible for the collapse of fish stocks and destruction or alteration of important freshwater habitats all over the world.

Habitat loss, degradation and fragmentation in freshwater ecosystems are a consequence of alterations in land use, such as conversion to agriculture, construction on margins, diversion and abstraction of water for human use and human intervention on the riverbed [i.e., channelisation, dredging activities or inaccessibility caused by physical barriers (e.g., dams)]. Such situations may disrupt migration to suitable areas for reproduction - especially for migratory fish, or feeding. In addition, impoundments affect both longitudinal and lateral connectivity, altering the natural hydrologic regimes and thus affecting the fish community negatively.

Species have been translocated or introduced into new systems throughout the world for different purposes (e.g., stocking for aquaculture and fisheries, sport fishing, release of aquarium species, environmental management or frivolously - out of fun, for instance). During recent years, the number of nonnative species introduced to freshwater ecosystems has increased considerably. Non-native species may impact aquatic ecosystems at the individual (e.g., altering the behaviour of native species, influencing habitat use and foraging, hybridisation), population (e.g., changing abundance, biomass and distribution of other species), community (e.g., altering interactions among populations and potentially inducing trophic cascades) and ecosystem (e.g., changing

Correspondence: C. Antunes, CIMAR-LA/CIIMAR - Interdisciplinary Centre of Marine and Environmental Research, University of Porto, Rua dos Bragas 289, 4050-123 Porto, Portugal. E-mail: cantunes@ciimar.up.pt 


\section{Editorial}

pathways and magnitude of energy and nutrients cycling) levels. The potential impact of the nonnative species depends upon the abundance, biomass, range and functional distinctiveness of the invaders, resident biota and environmental conditions, as well as time since invasion (Sousa et al. 2011). Additionally, biotic homogenisation - replacement of native biota by locally expanding non-native species, rapidly diminishes the regional distinctiveness of aquatic systems (Olden \& LeRoy Poff 2004).

Climate change may be responsible for future alterations in thermal and hydrologic regimes which may affect freshwater fish. Future temperature increments present potentially great impacts on fish populations - particularly those at the edge of their natural distributional ranges. For instance, fish species would be at risk when habitat fragmentation makes migration to more favourable, higher latitudes/altitudes habitats impossible. Moreover, predicted increased intensity of extreme climatic events (e.g., droughts and floods) will also affect fish communities. Notably, some of the mentioned effects remain speculative, and studies addressing the possible effects of climate change are scarce, thereby impairing our predictive ability to project future changes.

Due to human activities, freshwater ecosystems have been used loosely as waste recipients for many kinds of pollutants, for example, nutrients, heavy metals, 'emergent' pollutants - PCBs, PBDEs, dioxins, nanoparticles and endocrine disruptors, etc. These pollutants may accumulate in fish and be responsible for acute or chronic effects with possible negative impacts at different ecological levels. Increased efforts (e.g., new legislation) by several developed countries have managed to reduce the discharge of these pollutants into the freshwater ecosystems; however no such information could be gathered from the developing countries.

Freshwater ecosystems have been severely damaged or altered in the last decades at a rate greater than any other period in the human history (Dudgeon et al. 2006). Therefore, major efforts in terms of ecological rehabilitation of water bodies are required in order for fish diversity to persist and prosper (Kottelat \& Freyhof 2007). However, the implementation of management and conservation measures is difficult. This is because of the myriad of threats and their possible interplay; but also due to the particular position of freshwater ecosystems in the landscape as receptors of all kind of damages. The developed countries are aware of the gravity of the situation that is affecting the freshwater ecosystems and have implemented several measures/strategies to protect and preserve them, or at the very least amended some of their social and political conditions to help pave way for possible improvements to be made in future. There are a number of practices that are commonly implemented and could include the construction of fish bypass in dams, demolition of obstacles, restoration of natural conditions, treatment for sewage prior to release into the environment, eradication and control of nonnative species, restoration programmes and stocking of native threatened species, and strict regulations on fishing. The creation of nonfishing areas - similar to marine protected areas, in sensitive freshwater habitats could also be an important measure. However, issues like financial constraints and overpopulation in developing countries have made these management options more difficult to implement in those regions and thus leaving the abovementioned threats continuing to affect the freshwater fish. Thus joint efforts between scientists, stakeholders and international funding agencies are urgently needed as these developing regions are recognised as hotspots for fish biodiversity.

The Ecology and Conservation of Freshwater Fish (ECFF 2012) conference showcased the most recent studies on the ecology and conservation of freshwater fish and brought together 160 scientists from 29 countries to engage in the discussion of field-related state-of-the-art expertise and to find more effective management strategies to protect this faunal group. ECFF 2012 was held between 28 May and 1 June, in Vila Nova de Cerveira - a picturesque small village at the north of Portugal.

This issue presents nine studies that were presented at ECFF 2012 as a special issue section covering several major ecological aspects: population dynamics (MacNamara \& McCarthy 2014), toxicology (Pedro et al. 2014; Privitera et al. 2014), diet (Heermann et al. 2014; Taal et al. 2014), distribution/migration (Bass et al. 2014; Borcherding et al. 2014; Rohtla et al. 2014) and morphological aspects (Natsumeda et al. 2014) of freshwater fish. In addition to the ECFF conference, the 6th edition of the International Symposium of the Minho Basin was held on 2nd June. This bi-annual event is a forum for discussion among scientists, managers and members of the local community to debate recent scientific findings so as to better manage the natural resources in the Minho hydrologic basin.

Future possible areas of research on freshwater fish ecology and conservation are numerous and await further exploration, thus we strongly urge our colleagues to continue battling on in order to innovate the management of freshwater ecosystems and their resources. We hope that the ECFF 2012 and this special issue may contribute to enhance further studies addressing this faunal group and to capture the attention of policy makers, stakeholders, fishermen, managers and the general public. 


\section{References}

Allan, J.D., Abell, R., Hogan, Z., Revenga, C., Taylor, B.W., Welcomme, R.L. \& Winemiller, K. 2005. Overfishing of inland waters. BioScience 55: 1041-1051.

Bass, A.L., Haugen, T.O. \& Vøllestad, L.A. 2014. Distribution and movement of European grayling in a subarctic lake revealed by acoustic telemetry. Ecology of Freshwater Fish 23: 149-160.

Borcherding, J., Breukelaar, A.W., Winter, H.V. \& König, U. 2014. Spawning migration and larval drift of anadromous North Sea houting (Coregonus oxyrinchus) in the River IJssel, the Netherlands. Ecology of Freshwater Fish 23: 161-170.

Carpenter, S.R., Stanley, E.H. \& Vander Zanden, M.J. 2011. State of the world's freshwater ecosystems: physical, chemical, and biological changes. Annual Review of Environment and Resources 36: 75-99.

Dudgeon, D., Arthington, A.H., Gessner, M.O., Kawabata, Z., Knowler, D.J., Lévêque, C., Naiman, R.J., Prieur-Richard, A., Soto, D., Stiassny, M.L.J. \& Sullivan, C.A. 2006. Freshwater biodiversity: importance, threats, status and conservation challenges. Biological Reviews 81: 163-182.

Heermann, L., Scharf, W., van der Velde, G. \& Borcherding, J. 2014. Does the use of alternative food resources induce cannibalism in a size-structured fish population? Ecology of Freshwater Fish 23: 129-140.

Helfman, G.S., Collette, B.B., Facey, D.E. \& Bowen, B.W. 2009. The diversity of fishes - Second edition. Oxford, UK: John Wiley \& Sons. 736 pp.

Kottelat, M. \& Freyhof, J. 2007. Handbook of European freshwater fishes. Cornol, Switzerland: Kottelat and Berlin, Germany: Freyhof.

Lucas, M.C. \& Baras, E. 2001. Migration of freshwater fishes. Oxford, UK: Blackwell Science. 412 p.

MacNamara, R. \& McCarthy, T.K. 2014. Silver eel (Anguilla anguilla) population dynamics and production in the River Shannon, Ireland. Ecology of Freshwater Fish 23: 181-192.
Natsumeda, T., Tsuruta, T., Takeshima, H., Awata, S. \& Iguchi, K. 2014. Variation in morphological characteristics of Japanese fluvial sculpin related to different environmental conditions in a single river system in eastern Japan. Ecology of Freshwater Fish 23: 114-120.

Olden, J.D. \& LeRoy Poff, N. 2004. Ecological processes driving biotic homogenization: testing a mechanistic model using fish faunas. Ecology 85: 1867-1875.

Pedro, S., Caçador, I., Quintella, B.R., Lança, M.J. \& Almeida, P.R. 2014. Trace element accumulation in anadromous sea lamprey spawners. Ecology of Freshwater Fish 23: 193207.

Privitera, L., Aarestrup, K. \& Moore, A. 2014. Impact of a short-term exposure to tributyl phosphate on morphology, physiology and migratory behaviour of European eels during the transition from freshwater to the marine environment. Ecology of Freshwater Fish 23: 171-180.

Rohtla, M., Vetemaa, M., Taal, I., Svirgsden, R., Urtson, K., Saks, L., Verliin, A., Kesler, M. \& Saat, T. 2014. Life history of anadromous burbot (Lota lota, Linneaus) in the brackish Baltic Sea inferred from otolith microchemistry. Ecology of Freshwater Fish 23: 141-148.

Sousa, R., Morais, P., Dias, E. \& Antunes, C. 2011. Biological invasions and ecosystem functioning: time to merge. Biological Invasions 13: 1055-1058.

Taal, I., Saks, L., Nedolgova, S., Verliin, A., Kesler, M., Jürgens, K., Svirgsden, R., Vetemaa, M. \& Saat, M. 2014. Diet composition of smelt Osmerus eperlanus (Linnaeus) in brackish near-shore ecosystem (Eru Bay, Baltic Sea). Ecology of Freshwater Fish 23: 121-128.

Vörösmarty, C.J., McIntyre, P.B., Gessner, M.O., Dudgeon, D., Prusevich, A., Green, P., Glidden, S., Bunn, S.E., Sullivan, C.A., Liemann, C.R. \& Davies, P.M. 2010. Global threats to human water security and river biodiversity. Nature 467: 555-561. 